NBER WORKING PAPER SERIES

\title{
THE FORECASTING ABILITY OF MONEY \\ MARKET FUND MANAGERS AND \\ ITS ECONOMIC VALUE
}

Alex Kane

Young $\mathrm{Ki}$ Lee

Working Paper No. 1243

\author{
NATIONAL BUREAU OF ECONOMIC RESEARCH \\ 1050 Massachusetts Avenue \\ Cambridge, MA 02138 \\ December 1983
}

We wish to thank Paul Berger, Alan Marcus, Robert McDonald and Don Smith for helpful discussions. The research reported here is part of the NBER's research program in Financial Markets and Monetary Economics. Any opinions expressed are those of the authors and not those of the National Bureau of Economic Research. 
The Forecasting Ability of Money Market Fund Managers and Its Economic Value

\section{ABSTRACT}

The model proposed by Merton(1981) to determine the value of forecasting ability is adapted to investigate whether money market fund managers successfully anticipate changes in the yield curve by adjusting the average maturity of their portfolios in the right direction. The potential economic value of such behavior is assessed, and it is shown that if the portfolios of all money market funds were aggregated it would appear that managers are good forecasters even if individually they possess insignificant forecasting ability. At the same time, the economic value of the aggregate portfolio will be diminished because of the reduced net change in average maturity. Thus, diversifying into many money market funds will not attain the gain that could be realized if an individual manager had a forecasting ability equal to the quality of the average forecast.

A sample of 34 money market funds is investigated. Analysis suggests that a small fraction of the funds exhibited forecasting skills, but even they generated negligible economic value because the changes in their portfolios average maturity were too small. There appears to be no relationship between forecasting ability and economic success of money market funds as measured by asset size and growth.

Alex Kane and Young Ki Lee School of Management Boston University 704 Commonwealth Avenue Boston, MA 02211 
THE FORECASTING ABILITY OF MONEY MARKET FUND MANAGERS

AND ITS ECONOMIC VALUE

\section{INTRODUCTION}

The performance of investment managers encompasses two elements: Microforecasting: the ability to forecast price movements of individual stocks and (2) Macroforecasting: the ability to forecast the performance of equities relative to fixed income securities.

Merton (1981) motivates the study of macroforecasting by demonstrating the staggering value of macroforecasting ability; using monthly returns of Treasury-bills and a portfolio invested in the NYSE for the period 1927-1978 he demonstrates that a manager who started with $\$ 1000$ in January 1927 and switched funds between these two assets every month with perfect foresight, would have produced by December 1978 a fund valued at approximately $\$ 5,400,000,000$ compared with approximately $\$ 67,000$ when consistently invested in the NYSE index. Such numbers explain the zeal of practitioners in attemptiong to tap this potential reward and attempts by students of finance to identify above-average macroforecasting talents.

Studies of macroforecasting prior to Merton's (1981) work ${ }^{1}$ used the capital asset pricing model (CAPM) to identify the element of macroforecasting in the overall performance. Merton (1981) and Henriksson and Merton (1981) develop a more general approach to measure macroforecasting ability.

All of these studies, however, share one common assumption, namely that managers allocate their funds to one risk-free asset and a portfolio chosen from a universe of risky securities. The nominally risk-free asset is 
commonly taken to be a Treasury-bill of maturity equal to the portfolio rebalancing interval. A large number of individual and institutional investors use money-market funds as proxies for risk-free investments. ${ }^{2}$ The keen competition among these money-market funds (MMF) for the investor's dollar inevitably leads to the question of another $k$ ind of macroforecasting ability, i.e., the prediction of short-term movements in the yield curve. The measurement and economic value of interest rate forecasting by MMF managers is the subject of this paper.

Two approaches to the study of this question have appeared in print so far, both by Ferr $i$ and Oberhelman (1981a, 1981b). In the earlier paper Ferr $i$ and Oberhelman (1981a) use the CAPM framework to measure the performance of MMFs as they would have with any other portfolio. The trouble with this approach when applied to MMFs is that it is quite sensitive to the choice of benchmark as discussed in Roll (1979). Roll raised the problem with reference to the identity of a benchmark risky portfolio when the performance of equity fund managers is measured. In analyzing the performance of MMFs the more relevant question is the identity of the efficient zero-beta portfolio and its expected return. The robustness of using T-bills as the benchmark zero-beta portfolio in the evaluation of the performance of (very low beta) portfolios of MMFs is unclear at this point.

In their later study, Ferri and Oberhelman (1981b) use an alternative, indirect approach. They argue that the attempt of MMF managers to apply yield curve forecasting to their portfolio decison results in a continuous adjustment of their portfolios' average maturity. Accordingly, they correlate changes in average maturity with subsequent changes in short-term interest rates to judge the forecasting ability of fund managers. Their conclusion is 
that, on average, MMF managers exhibit a significant ability to forecast changes in interest rates. In developing their methodology, however, Ferr $i$ and Oberhelman fail to avoid a number of important pitfalls which might be responsible for their results as will be discussed below.

The present paper uses Merton's (1981) methodology to test the MMF managers' ability to forecast interest rates. We take special care in identifying the nature of the changes in interest rates, the forecast of which is implied by changes in average maturities of MMF portfolios. In contrast to Ferri and Oberhelman (1981b), we do not use the aggregate MMF portfolio. Rather, we explore the change in average maturity of individual MMF portfolios relative to subsequent changes in interest rates.

In developing the methodology we estimate the potential earnings to MMFs from interest rate forecasting using T-bill and CD data for the 1978-1981 period. We find that the performance of the majority of the MMFs in our sample of 34 funds did not exhibit a significant ability to forecast changes in interest rates over the test period of 1978-1981. At the same time, however, we find that a few funds exhibited such ability to a statistically significant degree. Still, because of the low magnitude of the actual changes in their portfolio maturities, even those funds could not achieve anywhere near the potential economic performance (in terms of rates of return earned) that would have been possible with such ability. 3

We also explain how the aggregation procedure can account for the upbeat results of Ferri and Oberhelman (1981b). Section II develops the methodology of the tests. Results are presented in section III. Section IV concludes. 
II. METHODOLOGY

In this paper we take the approach that the forecasting ability of MMF managers manifests itself in the changes they make in the maturity structure of their portfolio. "Forecasting changes in interest rates," however, is not a clearly defined concept. MMF managers are, at least implicitly, concerned with changes in the whole relevant range of the term structure of interest rates (i.e., up to maturity of 1 year) and thus their appropriate response consists of changes in the full-blown maturity structure of their portfolios. In empirical research it would be next to impossible to correlate changes in the entire maturity strucutre of portfolios with the subsequent change in the entire yield curve. In restricting the nature of the test to some practical measure one jeopardizes its validity. Thus we first turn our attention to this issue.

\section{II.1 RELATING CHANGES IN AVERAGE MATURITY TO SUBSEQUENT CHANGES IN INTEREST}

RATES

Ferri and Oberhelman (1981b) measure changes in average maturity which take place over the last one and two weeks of every month. They go on to measure changes in the yield to maturity of 90-day securities ${ }^{4}$ over the next one and two months. A successful prediction is recorded if a $r$ ise in the 90-day yield was preceded by a shortening of the MMF average maturity and vice versa. This experiment is perfectly valid if the yield curve always remains flat over the MMF's maturity range. Since the yield curve is, in general, neither flat nor affected by a mere shift upward or downward, such an experiment, henceforth referred to as the yield experiment, is of limited validity. In particular it is possible that the current forecast of a MMF 
manager is for 90 day rates to go up over the prediction horizon, yet lengthening the average maturity of the portfolio would still yield a better rate of return than leaving it unchanged. Two possible cases are shown in Figure 1. In both cases, $1(a)$ and $1(b)$, the initial yield curve, $y_{0}(t)$, is flat and in both cases 90-day yields in the subsequent yield curve $y_{1}^{d}(t)$ and $y_{1}^{b}(t)$, are actually higher. However, the nature of the change in the entire yield curve for bonds of initial maturity $M_{0}^{a}$ and $M_{0}^{b}$, respectively, is such that they could improve their holding period return by lengthening their average maturity to $M_{1}^{a}$ and $M_{1}^{b}$.

An alternative experiment restricts the changes in the yield curve over the holding period to a more general class. Denote the price, at time $s$, of a pure discount bond with maturity, $T$, by $P(s, T)$. With a holding period, $t$, the final price is $P(s+t, T-t)$ and the holding period return is

$$
R(s+t, T)=\frac{P(s+t, T-t)}{P(s, T)}-1
$$

The alternative experiment requires that changes in the yield curve during the interval $\left(s, s^{+} t\right)$ are such that the rate of return on any pure discount bond with maturity, $T$, will be equal to that of a two-bond benchmark portfolio with maturities $T_{1}, T_{2}$ so that

$$
R(s+t, T)=x R\left(s+t, T_{1}\right)+(1-x) R\left(s+t, T_{2}\right)
$$

where 


$$
x=\frac{T-T_{2}}{T_{1}-T_{2}}
$$

For this condition to hold it is necessary that holding period returns be linear in maturity, i.e.,

$$
R(s, T)=a_{s}+b_{s} T
$$

In order to see the restriction on changes in the yield curve imposed by this assumption, denote the annual, continuously compounded yield to maturity at time $s$ for any maturity by $Y(S, T)$. Then:

$$
P(S, T)=\exp [-Y(S, T) T]
$$

and

$$
R(s+t, T)=\exp [Y(s, T) T-Y(s+t, T-t)(T-t)]-1
$$

The linearity of $R(s+t, T)$ in $T$, together with (3), requires that

$$
Y(s+t, T-t) \frac{T-t}{T}=Y(s, T)-\frac{1}{T} \log (a+b T)
$$

Thus the validity of the experiment requires that changes in the yield curve will be limited to a two-parameter shift given by: ${ }^{5}-\log (a+b T)$ and forecasters are required to forecast the parameters $(a, b)$. This experiment is 
more general than the yield experiment which restricts $b=0$ and accounts for the initial maturity so that it does not suffer pitfalls as demonstrated in Figure 1 .

For this experiment in the present study (henceforth called the rate of return experiment) we chose for the benchmark portfolio the maturities $T_{1}=30$ days, $T_{2}=90$ days and the holding period $t=7$ days. Thus we recorded a successful prediction whenever a decrease in average maturity for a MMF over a given week was followed by $R(7,30)>R(7,90)$ for the next week and vice versa.

We undertook to measure the importance of the nature of the experiment by correlating the weekly indicated change in average maturity under these two alternative experiments. To reiterate, if one uses the yield experiment, then a successful prediction is recorded when an increase (decrease) in 90-day yields over a given week is preceded by a decrease (increase) in the average maturity of a MMF portfolio. If, on the other hand, one uses the rate of return test (on 30-vs. 90-day bonds), then a successful prediction is recorded when a higher (lower) rate of return on 30-day bonds (relative to 90-day bonds) over a given week is preceded by a decrease (increase) in the average maturity of a MMF portfolio.

Analysis of the indicated direction of the change in average maturity for the two experiments over the sample period is presented in Table 1 . As Table 1 indicates, the two methods of measuring changes in the yield curve prescribed identical maturity changes (in direction) for 173 out of 206 week s (84.0 percent) for T-bill portfolios and for 101 out of 163 weeks $(62.0$ percent) for Certificates of Deposit portfolios. Since CDs constitute the larger share of MMF holdings in the sample (see Table 2), the 62 percent agreement is more indicative of the possible loss of validity in concentrating 
on only one of these experiments above. One could seriously misjudge the prediction of MMF managers from average maturity changes by choosing, arbitrarily, one of these two possible experiments (as well as, perhaps, others). In the study we use only periods (weeks) for which both measurements of interest rate changes would have led to the same direction of the change in average maturity. It is assumed that when these two measurements agree it is unlikely that the nature of the actual changes in the entire yield curve over these weeks were such that they would have indicated opposite changes in average maturity in preceding weeks.

We now turn to the issue of the types of securities acutally held by the MMFs .

\section{I.2 THE INTEREST BEARING SECURITIES USED TO MEASURE CHANGES IN THE YIELD}

\section{CURVE}

MMFs hold, for the most part, three types of securities: Treasury bills $(T B)$, bank certificates of deposit (CD), and commercial papers (CP). These securities are not identical, as evidenced by their risk premia. Figure 2 shows the risk premia of 90-day CDs over TBs of equal maturities. The graph demonstrates that the type of bond used to measure yields is important. The relative holdings of these securiteis by MMFs has been changing markedly over time, as is indicated in Table 2 .

In order to examine how important it is to use the appropriate bonds when recording successful and unsuccessful changes in maturities, we contrast the prescribed direction of the change in average maturity when the yield (or the rate of return) method is applied to any of the three types of bonds. Table 3 presents the results for the yield experiment, which were similar to those of 
the rate of return experiments. Comparing the consistency of prescribed changes with the most widely held MMF securities, Table 3(a) indicates that 24.7 percent of the weeks provide conflicting results. The consistency of measurement using $T B$ yields $v s . C P$ and $C D$ is even worse, with 34.4 percent and 27.1 percent, respectively, conflicting prescriptions. These results raise another problem with Ferri and Oberhelman's (1981b) study which uses CDs only. In order to avoid the loss of validity due to different security holdings by various MMFs, we concentrate on periods for which the indicated changes in average maturity (as measured with both alternative ways) for a 11 three security holders agree.

So far we opted to restrict the observations to weeks when a successful change in average maturity is indicated by both the yield and the rate of return experiments (section II.1) and to those when the same successful change applies to all three major securities: TB, CD, and CP. Table 4 summarizes the number of available observations and reemphasizes the pitfalls from using observations indiscriminately.

The analysis of maturity changes by MMFs that was conducted by Ferr $i$ and Oberhelman concerns the average portfolio of all MMFs in their sample. Consequently they argue that their favorable conclusion applies to the average fund. The validity of this assessment is addressed next.

II.3 SHOULD MMF PORTFOLIOS BE AGGREGATED IN AN EXPERIMENT TO DETERMINE OVERALL FORECASTING ABILITY BY MANAGERS

Consider a population of $\mathrm{N}$ forecasters who are trying to predict the outcomes of a binomial process, 


$$
x_{t} \sim B\left(0,1 ; P_{t}\right)
$$

Suppose that $m$ of the $N$ forecasters are identical and superior to the other $n=N-m$ forescasters, who are identical also. For simplicity, assume that the unconditional probability $P_{t}=.5$ for all $t$ and that the $m$ superior forecasters issue forecasts

$$
Y_{i t}^{m} \sim B\left(0,1 ; P_{i}\right)
$$

with conditional probabilities of correct forecasts,

$$
P_{1}^{m}=\operatorname{Pr}\left(r_{i t}^{m}=0 \backslash x_{t}=0\right)=P_{2}^{m}=\operatorname{Pr}\left(y_{i t}^{m} t=1 \mid x_{t}=1\right)=.5+e_{m}
$$

for $i=1, \ldots, m$ while the inferior forecasters issue forecasts $y_{j t}^{n}$ with

$$
P_{1}^{n}=\operatorname{Pr}\left(Y_{j t}^{n}=0 \mid x_{t}=0\right)=P_{2}^{n}=\operatorname{Pr}\left(Y_{j t}^{n}=1 \mid x_{t}=1\right)=.5+e_{n}
$$

for $j=m+1, \ldots, N$ and $1 \geq e_{m}>e_{n} \geq 0$.

In this symmetric case the correlation coefficient between any forecast $y_{\text {it }}^{k}(k=m, n)$ and the actual outcome $x_{t}$ is a statistic of the forecaster's ability and is given by,

$$
\rho^{k}=\operatorname{Corr}\left(y_{i t}^{k}, x_{t}\right)=p_{1}^{k}+p_{2}^{k}-1=2 e_{k}
$$


for $i=1, \ldots, N$, and $k=m, n$, so that $e_{k}=0 \Rightarrow \rho_{i}^{k}=0$ and $e_{k}=.5$ $\Rightarrow \rho_{i}^{k}=1$ as expected. The relevant question is what happens when the forecasts are aggretated. Suppose that a user of the forecasts does not know the superior from the inferior forecasters and hence uses a simple average,

$$
Y_{t}=\frac{1}{N} \sum_{i=1}^{N} Y_{i t}=\frac{1}{N}\left(\sum_{i=1}^{m} Y_{i t}^{m}+\sum_{j=m+1}^{N} Y_{j t}^{m}\right)
$$

In order to determine the properties of the aggregate forecast one has to know the dependence structure. We assume that the conditional forecasts

$$
\mathrm{r}_{\mathrm{it}}^{\mathrm{k}} \mid \mathrm{X}_{\mathrm{t}} ; \quad \mathrm{i}=1, \ldots, \mathrm{N} \text { and } \mathrm{k}=\mathrm{m}, \mathrm{n}
$$

are independent. This means that the unconditional forecasts are dependent. In particular, the correlation coefficient between any two forecasts at time $t$ is

$$
o\left(Y_{i t}^{k}, Y_{j t}^{1}\right)=4 e_{k} e_{1} ; \quad k, 1=m, n
$$

so that when $e_{m}=e_{n}=1 / 2$, the correlation is perfect, etc. Under these circumstances the correlation between the average forecast, $Y_{t}$, and the realization, $x_{t}$, is:

$$
\rho\left(y_{t}, x_{t}\right)=\frac{m e_{m+} n e_{n}}{\left[N / 4+\left(m e_{m}+n e_{n}\right)^{2}-\left(m e_{m}^{2}+n e_{n}^{2}\right)\right]^{1 / 2}}
$$


Consider first the case when all forecasters are identical, i.e., $m=0$ and $n=N$. Then,

$$
o\left(Y_{t}, X_{t}\right)=\frac{e_{n}}{\left[e_{n}^{2}+(1 / N)\left(1 / 4-e_{n}^{2}\right)\right]^{1 / 2}}
$$

This expression reveals that if the forecasters have absolutely no forecsting ability, i.e.s $e_{n}=0$, their number will make no difference. If, however, they have some ability, however small, $e_{n}>0$, then

$$
\lim _{N \rightarrow} \rho\left(Y_{t}, x_{t}\right)=1
$$

This result gives us the first idea about results from aggregate forecasts. A small forecasting ability of individual managers can generate a powerful average forecast when many forecasts are used. Since most investors do not diversify MMF holdings among many funds, the performance of the average forecasts might be a misleading statistic. For concreteness, consider the results reported by Ferri and Oberhelman (1981b). They report a measure of association of $Q=.28$ between the direction of the change in the maturity of the average MMF portfolio and the subsequent direction of change in 90-day $C D$ yield. Using the conditional probabilities of $P_{1}, P_{2}$ for the average MMF forecast of yield changes, their measure of association, $Q$, is defined as: ${ }^{6}$ 


$$
Q=\frac{P_{1} P_{2}-\left(1-P_{1}\right)\left(1-P_{2}\right)}{P_{1} P_{2}+\left(1-P_{1}\right)\left(1-P_{2}\right)}
$$

Let us assume that this portfolio exhibits symmetry in forecasting ability, i.e., $P_{1}=P_{2}=.5+e$, then

$$
Q=\frac{2 e}{1 / 2+2 e^{2}}
$$

With a single forecaster's ability, e, the correlation between the forecast, $Y_{i t}$, and the realization, $x_{t}$, is

$$
\rho\left(Y_{i t}, X_{t}\right)=2 e
$$

and hence

$$
\rho=\frac{1-\left(1-0^{2}\right)^{1 / 2}}{0}
$$

Thus, for $Q=.28$ we arrive at $\rho=.14$. If we assume, again, that the individual managers are identical and issue conditionally independent forecasts we can use (9) to infer the individual forecasting ablity, $e_{n}$. The number of MMFs in Ferri and Oberhelman's study varies over the sample period 1975-1980. If we take a reasonable average number of $N=50$ MMFs, then (9) produces a low individual forecasting ability of $e_{n}=.01$, i.e., 
$P^{*}=P_{1}+P_{2}-1=2 e_{n}=1.02$. As we will show later, such ability has little economic value. In our sample of 34 MMFs with weekly data for the period 1978-1981, the sample average $P *$ for all MMFs was 0.11 and assuming symmetry and identical ability it implies $e_{n}=.055$. Using (9), we expect a correlation coefficient for the average forecast of $\rho=.54$, implying $e=.27$ and $P *=0.54$. The actual statistic for the average portfolio was $P *=0.43$. To check whether the actual lower figure is due to the heterogeneity of the sample we assumed it consists of two classes of identical superior and inferior forecasters. Out of 34 MMFs, the best four exhibited an average $P^{*}=$ 0.38 , all significant at the 1 percent level. The best eight exhibited an average $P^{*}=0.31$, all significant at the 5 percent level or better. Table 5 presents the implied quality of the average forecast and demonstrates that the actual lower average forecast quality is probably not due to the assumption of homogeneity. Another cause might be some positive conditional dependence of the MMFs forecast -- an issue which is left to a later section.

All in all, the foregoing analysis shows that measuring aggregate performance may serve as a powerful test to discover weak forecasting ability among many forecasters. It should not, however, be misinterpreted as indicative of strong individual ability from the quality of the average forecast. In the present study we concentrate on the individual ability of MMF managements.

We now turn to the discussion of the economic value and the measure to be used for the individual forecasting ability of MMFs. 


\section{II.4 THE PERFORMANCE MEASURE AND ECONOMIC VALUE OF MMF MANAGEMENTS' YIELD} FORECASTING

The state of the art of the determination of the economic value of forecasting ability (applied to stock market timing) is found in Merton (1981). The case examined by Merton involves a portfolio manager who limits his activity to the allocation of investment funds between a risk-free security and a prespecified risky asset, say, the market portfolio. At any time, $t$, with a horizon of $T$ periods, the manager compares the known gross yield to maturity on the $r$ isk-free asset, $R(t)=1+r(t)$, with his forecast of the gross rate of return on the risky portfolio, $z(t)=1+z(t)$. Defining perfect foresight as the ability to choose the security with the higher ex-post rate of return, Merton shows that a dollar invested by a manager with perfect foresight yields a rate of return identical to that of a portfolio consisting of a dollar invested in the risky security plus a call option, valued at $c(t)$, on a $\$ 1$ share in the $r$ isky portfolio, with maturity $T$ and excercise price $R(t)^{7}$. Therefore, the economic value expressed as a rate of return premium to perfect foresight is given by, 8

$$
c(t)=2 N\left[(1 / 2) \sigma_{Z}(t) T^{1 / 2}\right]-1
$$

where $N[$.$] is the cumulative standard normal distribution function, \sigma_{z}$ is the standard deviation of the rate of return on the risky portfolio and the formula (14) is a simplification of the Black-Schole's call option valuation formula when the exercise price equals the risk-free rate.

For our purpose we need to adapt the model to a case where the MMF manager chooses between two prespecified risky securities, say a 30- and a 90-day 
$T-b i 11$. Let $Z(t)$ correspond to the rate of return on the longer term and $R(t)$ to the stochastic rate of return on the shorter term bond. With perfect foresight defined as before, a dollar invested by the manager will yield a rate of return identical to that of a portfolio consisting of $\$ 1$ invested in the short term bond plus a call option on a $\$ 1$ position in the long term bond with the call maturity $T$ and stochastic exercise price $R(t)$. The economic value of perfect foresight under these conditions is therefore derived from the value of a call option with a stochastic exercise price [Merton (1973), Fisher (1978)]. Suppose that the price dynamics of the short term bond is described by: ${ }^{9}$

$$
d B(t)=B(t) \alpha_{R} d t+B(t) \sigma_{R} d W_{R}
$$

The actual gross holding period rate of return on the bond over the interval $(t, t+T)$ is

$$
\tilde{R}(t)=\frac{B(t+T)}{B(t)}=\exp \left[\alpha_{R} T+\frac{1}{2} \sigma_{R}^{2} t^{t+T} d W_{R}\right]
$$

with expectation $R(t)=\exp \left(\alpha_{R} T\right)$. The stochastic exercise price for the call on the longer term bond is $\exp [R(t)-1]$ which, following Merton (1981), we approximate by $R(t)$. The realized holding period rate of return on the longer term bond is 


$$
\tilde{Z}(t)=\exp \left[\alpha_{Z} T+\frac{1}{2} \sigma_{Z}^{2} t^{t+T} d W_{Z}\right]
$$

with expectation $Z(t)=\exp \left(\alpha_{Z} T\right)$. Define

$$
s^{2}(t)=\sigma_{R}^{2}+\sigma_{Z}^{2}-2 \rho \sigma_{r} \sigma_{R}
$$

where $s^{2}(t)$ is the variance rate of the difference between the rates of return on the long and short=term bonds and $\rho$ is the correlation coefficient between $d W_{R}$ and $d W_{Z}$. With these parameters the economic value of perfect foresight management given by (14) in Merton's (1981) case becomes here,

$$
c(t)=2 N\left[\frac{1}{2} s(t) T^{1 / 2}\right]-1
$$

To measure the economic value of perfect foresight management by MMF managers, we first observed actual weekly T-bill prices over the period 1978-1981. Specifically, we observed maturities as close as possible to 23 , 30,83 and 90 days so that, for example, the continuously compounded holding period return on a 30-day T-bill over week $t$ is: $\log B(t, 23) / B(t-1,30)$. We then computed the annual realized rate of return for three strategies: hold the 30-day T-bill, (ii) hold the 90-day bill, (iii) hold the bill which yielded the higher ex-post rate for each week. The results of this experiment for the overall period and two sub-periods are presented in Table 6 . For the overall period of 1978-1981 the realized annual rates of return on 30 - and 90-day bills were 10.26 and 10.80 percent, respectively, and we assume that the difference of .56 percent per annum represents risk adjustment. On 
the other hand, the return of 12.28 percent to the perfect foresight strategy reflects a risk-free premium of 2.02 percent per annum to perfect foresight management.

It is well known [Bodie, Kane and McDonald, (1983)] that interest rates became more volatile (to date) since October 1979, a fact which is also reflected in the table. Commensurately, the premium that would have been realized with perfect foresight over the period 1980-81 is 3.24 percent per year. Note that the standard deviation for the difference between the realized rates on 30 - and 90 -day bills is .72 percent and .94 percent per annum for the overall period and the 1980-81 subperiod, respectively. These standard deviations reflect a correlation coefficient between the rates of 0.75. Substituting these estimates for $s(t)$ in $(15)$, we obtain a theoretical estimate of the premium to perfect foresight as 2.11 percent for the overall period and 2.75 percent for the 1980-81 period. The theoretical estimates of the premia from (15) are more reliable than the measured premia because the latter depend on the variance estimate alone (see Merton, 1980), while the empirical ex post measures assume that the period averages equal ex ante means. We repeated the same experiment for CD strategies. This experiment has the empirical problem of lack of data for the 23- and 83-day maturities. Thus, we approximated $B_{C D}(t, 23)$ and $B_{C D}(t, 83)$ by $B_{C D}(t, 30)$ and ${ }^{B}{ }_{C D}(t, 90)$. Because of these less reliable estimates, we only report here that the estimate of the theoretical premium to perfect foresight with CDs is 2.75 percent over the 1978-81 period (compared to 2.11 percent for T-bills), reflecting a slightly greater variance of CD rates and therefore greater forecasting value.

It is interesting to speculate on the value of perfect foresight if, for 
the longer bond, managers used a 180-day instead of a 90-day maturity. ${ }^{10}$ We use the assumption underlying the validity of the rate of return experiment, stated by (2) and (4), i.e., that the 180-day T-bill rate is given by:

$$
R(t, 180)=-1.5 R(t, 30)+2.5 R(t, 90)
$$

Thus, using the variance and correlation estimates for $R(t, 30)$ and $R(t, 90)$, we obtained a standard deviation for the difference $R(t, 180)-R(t, 30)$ of 1.72 percent for the 1978-81 period. Substituting this figure into (15) yields a perfect foresight premium of 5.07 percent per year..$^{11}$ Between 1978-79 and 1980-81 periods, MMFs shortened their average maturities reflecting, at least, a recognition on their part of less than perfect foresight ability which led them to forego the larger potential gains.

Merton (1981) goes on to prove that with less than perfect foresight, the conditional probabilities:

$$
\begin{aligned}
& P_{1}=\operatorname{Pr} \text { (lengthen maturity ex-post justified) } \\
& P_{2}=\operatorname{Pr} \text { (shorten maturity ex-post justified) }
\end{aligned}
$$

provide sufficient information to assign economic value to their forecasting ability. In particular, $P^{*}=P_{1}+P_{2}-1$ is a sufficient statistic for that value which implies that the symmetry in ability $\left(P_{1}=P_{2}\right)$ is of no importance, as well as the symmetry in realization, i.e., whether one outcome is more frequent. Thus the value of the forecast in (15) adapted to a specific forecasting ability is $P^{*} C(t)$.

Finally, Merton considers the value of forecasting ability when not all 
funds are switched according to the forecast. Specifically, when $x_{R}$ is invested in the short bond when the forecast is favorable to it (and $1-x_{k}$ in the less favorable long bond) and $x_{k}$ is invested in the short bond when the forecast favors the long bond, then the value of the forecast becomes: ${ }^{12}$

$$
m(t)=\Delta(t) P \star c(t)
$$

where $\Delta(t)=x_{h}(t)-x_{k}(t)$. In our case by (2),

$$
x_{m}=\left(T_{k}-T_{2}\right) /\left(T_{1}-T_{2}\right) \quad \text { for } m=h, k
$$

Hence $x_{h}-x_{k}=\left(T_{R}-T_{k}\right) /\left(T_{1}-T_{2}\right)$ and thus the value of forecasting ability is prportonal to the change in average maturity as a proportion of the maturity difference in the bench mark bonds. 13

Armed with these results we are able to analyze the actual data from our MMFs sample.

\section{PERFORMANCE EVALUATION OF THE MONEY MARKET FUNDS OVER THE PERIOD}

\section{$1978-1981$}

\section{III.1 The Sample Data}

The MMF maturity data were obtained from the Donoghue Money Market Fund report for the period 1978-1981. We kept in the sample all MMFs (34 funds) for which the average maturity was included in all reports. The Report also lists, in addition to the average maturity, the market value of the portfolio of the MMFs. 
As explained earlier, the weekly observations had to be trimmed down to include only weeks for which the favorable change in average maturity is unambiguous by our assumption about the nature of the change in the yield curve. The overall number of weeks which qualified for performance measurement is given in Table 4. The overall number of avaialble weeks (69) is not distributed evenly over the period. Table 4 also shows the breakdown for the two-year subperiods, 1978-79 and 1980-81. The relatively low number of available weeks for the period 1978-79 (24) renders estimates for this subperiod less reliable.

Week ly 90-day yields-to-maturity and realized rates of return on T-bills and CDS of 30- and 90-day maturities were taken from the Wall Street Journal. The 90-day CP yields were obtained from Business Week.

\section{III.2 Forecasting Ability}

Before we present estimates of forecasting ability we should qualify the results by stating that it is not established that all funds change maturity solely in an attempt to exploit yield curve forecasts. The need for liquidity and risk preference may, for some periods at least, be an important consideration. To this extent, estimatates that derive forecasting ability from maturity changes may be noisy and thus biased downwards in statistical signficance.

Table 7 summarizes the estimates of the conditional probabilities, $P_{1}$ and $P_{2}$, for the 34 MMFs in the sample for the overall period (1978-81) and the two-year subperiods. The bottom line of the table shows that, taking the aggregate portfolio of all MMFs, the combined forecast is potentially valuable. The statitistic $P *=P_{1}+P_{2}-1$ for the aggregate portfolio over 
the period is .43 , which means that if all funds were to be switched between the short and long maturity benchmark securities, these forecasts would retain 43 percent of the value of perfect foresight management. As was argued in Section 2.3, however, these results might be driven, at least in part, by the sheer number of the MMFs with even marginal forecasting ability. The two lines next to the bottom of the table show that the simple average of $p *$ for the 34 MMFs in the sample is .11 , and, when weighted by asset size, .17. (The difference is not statistically significant and the question of the relationshiup between $p *$ and asset size is discussed below.)

The estimates for the overall period show 8 MMFs with $P$ * statistics which are significantly different from zero, ranging from .63 to .22 . (Note that the aggregate portfolio performed better than the second best MMF.)

\section{III.3 The Consistency and Symmetry of the Estimated Forecasting Ability}

The rank correlation for $P$ * between the two subperiods is quite low $(.04)$ and not significantly different from zero. Because the low forecasting ability of most MMFs in the sample may be introducing noise into the correlation estimate, we also use a $2 \times 2$ chi-square test to check for consistency of $p *$ over the subperiods. The chi-square value from the test was .72 with 1 degree of freedom suggesting that there is no consistency in performance over the two subperiods. This result, however, has to be qualified due to the small number of observations in the early period $(1978-79)$.

Another interesting question is the symmetry of the estimated forecasting ability. Here, too, the problem with the aggregate portfolio shows up. The aggregate portfolio exhibits a signicantly better ability to forecast yield 
curve changes which favor a reduction in average maturity, i.e., $P_{1}=.81$, compared to those that favor an increase in average maturity, $P_{2}=.61$. But the estimates for the average MMF tell a different story. The difference between $P_{1}$ and $P_{2}$ is smaller and in the opposite direction. For the simple average, $P_{1}=.50$ and $P_{2}=.61$, and the difference is smaller for the weighted average $\left(P_{1}=.54, P_{2}=.62\right)$. These numbers suggest that MMF managers might be able to forecast better yield changes which favor lengthening the portfolio average maturity.

\section{II.4 Does the Sample Suggest that MMF Managers Are Able Forecasters}

The most important question concerning the estimates of $P \star$ for various MMFs (and their statistical significance) is: To what extent can these results be attributed to sampling phenomena. To be specific, Table 7 indicates that 9 MMFs exhibit $P *$ greater than .2, i.e., the potential value of their forecast is 20 percent (or better) of the value of perfect foresight. For each MMF the distribution of the $P \star$ statistic is hypergeometric (Henriksson and Merton, 1981). Suppose that for the $i-t h$ MMF we estimate $\alpha_{j}$ $=\operatorname{Pr}\left(P^{\star}>Q=.2 P^{\star}=0\right), i . e .$, the probability that with no forecasting ability a sample of observations will yield $P \star>.2$. Using the 34 estimtes of $\alpha_{i}$ we have the expected number, $n$, of MMFs with $P^{\star}>Q=.2$ (under $H_{0} ; P_{i}^{\star}=0$; for $i=1, \ldots, 34)$ as $E(n)=\alpha_{i}$.

The heavy line in Figure 3 represents the number of MMFs for which the estimated value exceeds various levels of $P \star$. The dashed line (the lowest line) represents the expected number of MMFs at each level of $P$ * assuming no forecasting ability on the part of all MMFs in the sample. From these two graphs one has to conclude that the nuber of "able" MMFs is beyond expectation 
under the null hypothesis of no forecasting ability. For $Q=.2$, for example, we have 9 MMFs which exceed it compared with 2 MMFs which could be expected to do so. To assess this inference we construct a graph for a 95 percent confidence interval above the expectation line in Figure 3 assuming that MMF forecasts are independent. This line, while lying well above the expectation line, still shows that some MMF managers have to be considered able forecasters. For $Q=.2$, the 95 percent confidence bound is only 5 compared to the actual (9).

One may question the assumption of independent forecsts, however. To establish the confidence interval with dependent forecasts we need to estimate $\operatorname{Var}(n)=\operatorname{Var}\left(\alpha_{i}\right)$ when $\operatorname{Corr}\left(\alpha_{i}, \alpha_{j}\right)=r_{i j}>0$. In this case, $\operatorname{Var}\left(\alpha_{i}\right)=$ $\sigma_{\alpha_{j}}^{2}+\sigma_{\alpha_{j}}^{2}+2 \sigma_{\alpha_{i}} \sigma_{\alpha_{j}} r_{i j}$. The correlation coefficient, $r_{i j}$, is a complex two two stage linear transformation of the correlation between forecasts, $\pi i j=$ $\operatorname{Corr}\left(Y_{i}, Y_{j}\right)$. First because $\alpha_{i}$ is a statistic with a binomial distribution and second because the $P_{i}^{*}$ statistics (underlying the $a_{j}$ ) is hypergeometrically distributed. Thus it requires a stretch of the imagination to use the forecast correlation matrix, $\pi_{i j}$, to infer $r_{i j}$. As a first step we consider the foundation of the independence assumption. This would require the independence of the conditional forecasts:

$$
\begin{aligned}
& \rho_{i j}(+)=\operatorname{Corr}\left(Y_{i}, Y_{j} \text { lengthening maturity is favorable }\right) \\
& \rho_{i j}(-)=\operatorname{Corr}\left(Y_{i}, Y_{j} \text { shortening maturity is favorable }\right)
\end{aligned}
$$

Table 8 indicates that both sets of conditional correlation coefficients appear to be distributed normally with a mean of .05 , which is statistically significant. It is interesting to check whether the conditional correlation 
coefficients are different among the top 8 MMFs. In Table 8 the mean of $\rho(-)$ is .08 and for $\rho(+)$ is .03 . In both cases the means are not significantly different from those of the overall sample. The correlation coefficients between the unconditional forecasts have a mean of .04 with a standard deviation of .082 (somewhat surprisingly) similar to those of the conditional forecasts. These correlation coefficients could be used to estimate the correlation between the $\alpha_{i}$ statistic $\left(r_{i j}\right)$ only if the transformation were linear. Yet, since the data suggest that the $\alpha_{j}$ must be correlated, we use these means as justification to present the range of $.05-.10$ for $r_{i j}$ in constructing the confidence limits as our best guess. The remaining two lines in Figure 3 show the 95 percent confidence limits based on $r_{i j}=.05$ and .10. The higher line of the two (for $r_{i j}=.10$ ) traces the actual graph almost exactly except for the single, top MMF which logged $p^{\star}=.62$. Thus the question of whether the forecasting ability demonstrated by the MMFs is just a sample phenomenon cannot be answered with confidence although the evidence seems to favor the hypthesis that a small number of MMF managers did exhibit superior forecasting skills.

\section{III.5 The Actual Economic Value of the MMFs Forecasting Ability}

It is tempting to try to relate the actual rates of return for the various MMFs to their demonstrated forecasting ability. A priori, the difficulties in this approach are mainly two: First, a good number of these funds use the amortized premium accounting method which would obscure any distinction of performance which is attributable to forecasting ability. Second, the constant change of the MMF' portfolio composition in terms of the various securities would make it impossible to separate the timing from the selection 
skills, if any. Finally, using actual returns would imply that ex post returns can be taken to reflect ex ante means. Thus we have to resort to the indirect method explained in Section 2.4, where we made additional use of Merton's (1981) mode1. We showed that under our assumptions, with the benchmark securities being T-bills of 30- and 90-day maturity, the economic value of their forecasting skills is given by $p \star_{c}(t)$. We have shown above that $c(t)$ is of the order of magnitude of 2 percent premium to the annual risk adjusted rate of return. There are 8 MMFs which exceed $P *=.22$ with statistical significance and hence could potentially realize 22-62 percent of that premium. What factor, $\Delta$, should be used for this potential annual gain of $P{ }^{\star} c(t)=.5-1.5$ percent? Table 9 presents the average change in maturity (in days) over the sample period. The first column shows the averages for the weeks used to measure performance. The first panel accounts for the overall period. These numbers show that the best four MMFs behaved similarly to the other 28. Using 3 days as the average change in maturity yields $\Delta=3 / 60=$ .05 , which is so low as to practically eliminate any potential gain from forecasting ability. Note also that the aggregate portfolio average change in maturity ( 1.73 days) reflects the interfund forecast variability and assures that whatever advantage one obtains from forecast averaging $(P \star=.43)$ might be lost by averaging the intended maturity change, since $\Delta \cong .03$.

We are led to conclude that even if some of the MMF managers have any forecasting ability they either lack in confidence or in recognition of their own skills or, more likely, are prevented by institutional constraints from taking advantage of them. The second column in Table 9 is presented for a good reason. It shows that the weeks used to measure performance are not significantly different in terms of maturity decisions from other weeks, and 
if at all, the changes during these weeks are actually smaller. Recall that the weeks used for performance evaluation are those for which the 90-day yield changes and the realized rate of return differential between 30- and 90-day securities of the three bond types (TB, CP, CD) all favor the same directional change in maturity. One expects these weeks to coincide with relatively severe changes in the yield curve. Table 10 shows that this is indeed the case. The changes in yields and rate of return differentials are double or more for the weeks used to measure performance. If it is easier to forecast more severe changes in the yieid curve, then our performance measurement in the preceding section is biased in favor of MMF managers. This, however, is probably not the case since changes in average maturity are not larger during these weeks, indicating that managers, at least, do not feel that way.

III.6 The Relationship Between Forecasting Ability and Asset Size and Growth

As Table 8 indicated, the weighted average of $P$ * for the MMF sample (.17) is higher than the simple average (.11). This raises the question of whether the managers of larger MMFs possess better forecasting skills. Since the management fee is proportional to asset size, one would expect that larger MMFs will be able to allocate more resources to yield curve forecasting and thus, if it is at all possible, should perform better. Table 11 suggests that this propostion is not supported by the evidence, either because larger MMFs do not allocate more resources to forecasting or that additional resources do not result in better forecasts. The simple and Spearman rank correlation coefficients between $P *$ and asset size either at the end of 1978 or 1981 are low and not significantly different from zero.

A related question is whether revealed forecasting ability results in the 
success of a MMF as a business, when measured by the rate of growth in asset size over the period 1978-81. The simple and rank correlation coefficients between $P^{*}$ and the magnitude of assets growth as show in Table 11 indicate that the answer to this question is also negative. This could be a result of the fact that investors recognize, as we showed earlier, that even MMFs with revealed forecasting ability did not generate any significant economic value. of course, one cannot reject the conclusion that forecasting ability goes unrewarded in the market place which, in turn, explains why the larger MMFs would not try harder, which in turn explains why there is no correlation between size and performance.

\section{SUMMARY AND CONCLUSIONS}

Previous investigation suggested that money market fund managers demonstrated ability to anticipate changes in short term yields by changing their portfolio average maturity in the direction considered consistent with subsequent changes in the yield curve. This paper demonstrated that the question was inadequately addressed by (i) aggregating the sample MMF portfolios, (ii) measuring their performance with inadequate statistics, (iii) determining the adequate direction of change on the basis of subsequent changes in the 90-day yield to maturity and (iv) using CDs as representative of the money market fund portfolio composition. We proceeded to observe the maturity behavior of individual money markt funds and adopted Merton's (1981) model to measure the forecasting skills and economic value of yield curve management by money market fund mangers.

We recorded the adequacy of changes in portfolio maturity in a way which is valid up to a two parameter shift in the yield curve. We used only weeks 
when the favorable direction of change in portfolio maturity is consistent for T-bills, CDS and CPs whether the benchmark is the subsequent change in the 90-day yield to matuirity or the difference in the realized rate of return on 30- vs. 90-day securities.

Results show that some funds do demonstrate forecasting ability. Measuring the average weekly change in maturity, however, shows that these were sufficiently small to devoid the demonstrated skills of any economic value. It was also shown that larger money market fund mangers do not demonstrate better forecasting skills and that, in turn, revealed forecasting skills are not rewarded by faster growth in the money market fund assets. 


\section{Figure 1}

Examples of Changes in Yield Curves from $Y_{O}(t)$ to $Y_{1}(t)$, which Favors Changes in Maturity of Same Direction as the Changes in 90 Day Yield.

(a)

Initial Maturity $M^{a}$ is Longer than 90 Bays

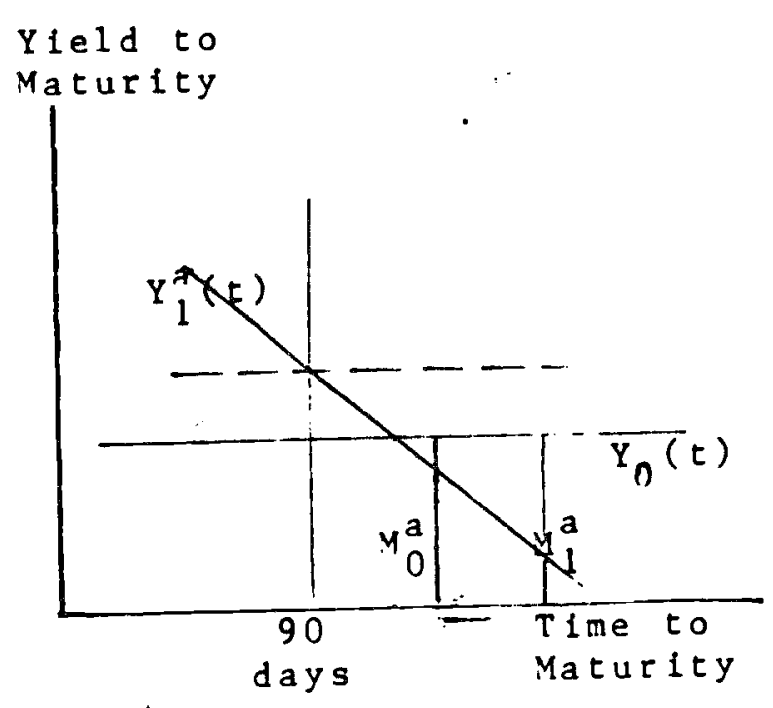

(b)
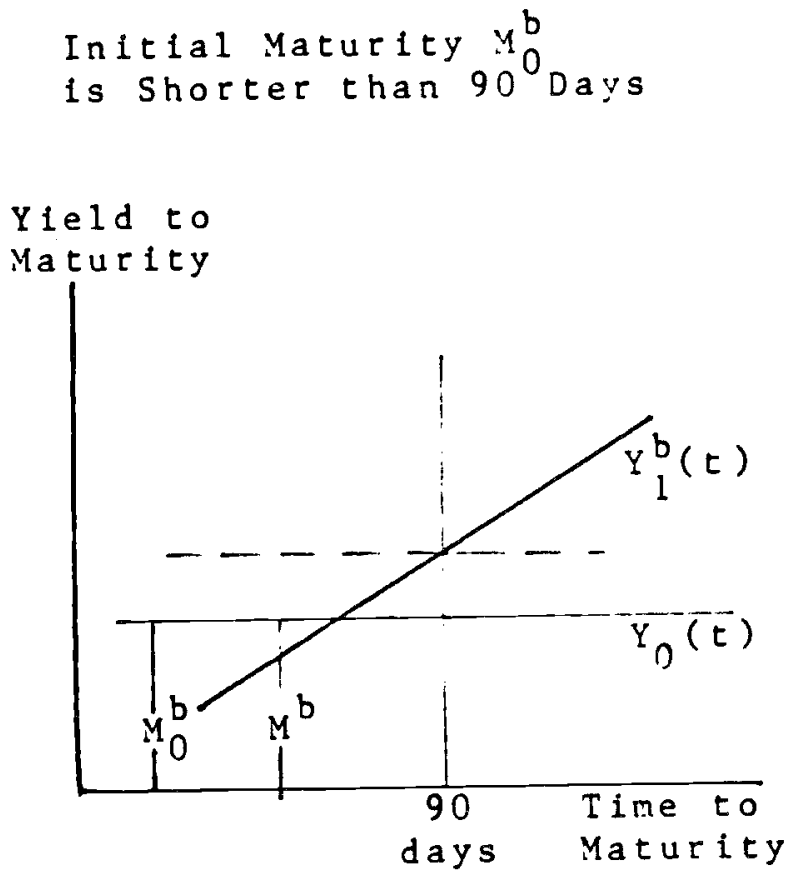
Figure 2

\section{DIFFERENCE BETWEEN 3 MONTH T-BILL AATES AND 9O DAY CD RATES SOLFCE - CAI}

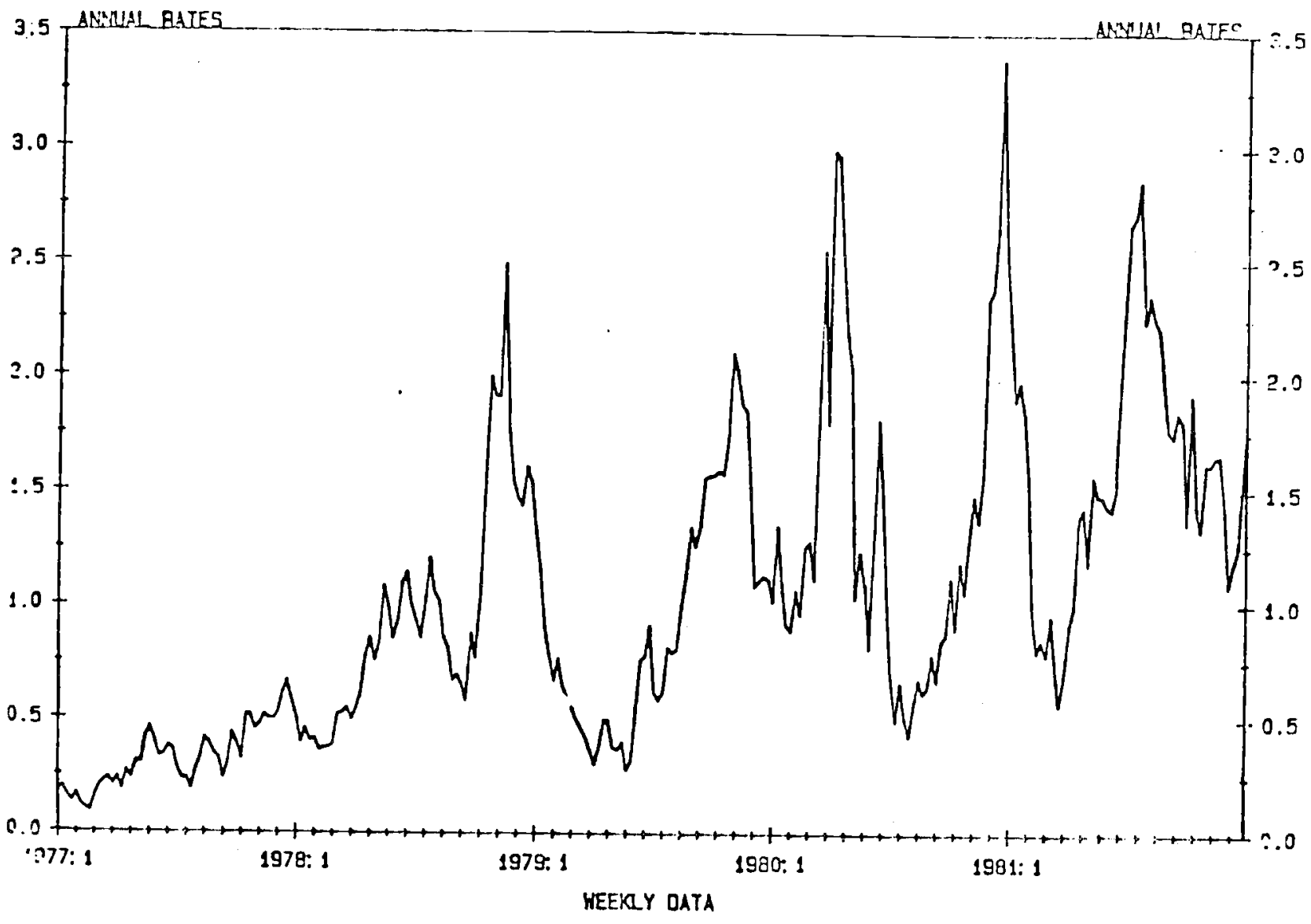


Eigure 3

Number of Funds Exceeding Various Levels of $P^{*}=P_{1}+P_{2}-1$
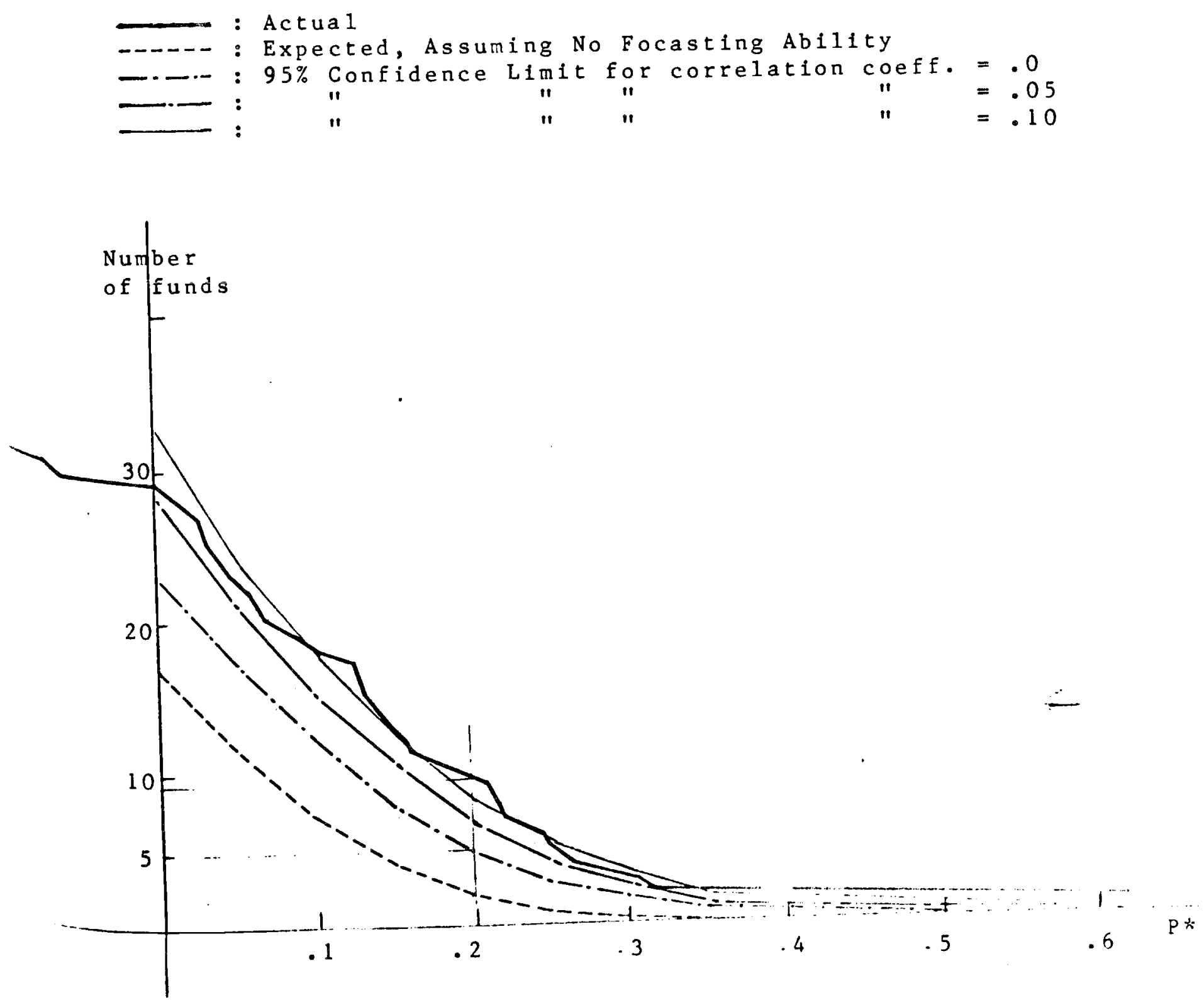
Table 1

Changes in Average Maturity Prescribed by Subsequent Changes in Interest Rates as Measured by the Yield Experiment and Rate of Return Experiment for TB and CD Portfolios

\begin{tabular}{|c|c|c|c|c|}
\hline \multirow{2}{*}{\multicolumn{2}{|c|}{$\begin{array}{l}\text { Indicated Changes in } \\
\text { Average Maturity } \\
\text { Prescribed by the } \\
\text { Rate of Return Method } \\
\end{array}$}} & \multicolumn{2}{|c|}{$\begin{array}{l}\text { Indicated Change in } \\
\text { Average Maturity } \\
\text { Prescr ibed by the } \\
\text { Yield Method } \\
\end{array}$} & \multirow[b]{2}{*}{$\begin{array}{l}\text { Total } \\
\text { Weeks }\end{array}$} \\
\hline & & Shorten & Lengthen & \\
\hline \multirow{3}{*}{$\begin{array}{l}\text { TB } \\
\text { Portfolios }\end{array}$} & Shorten & 80 & 6 & 86 \\
\hline & Lengthen & 27 & 93 & 120 \\
\hline & Total & 107 & 99 & 206 \\
\hline \multirow{3}{*}{$\begin{array}{l}C D \\
\text { Portfolios }\end{array}$} & Shorten & 55 & 15 & 70 \\
\hline & Lengthen & 47 & 46 & 93 \\
\hline & Total & 102 & 61 & 163 \\
\hline
\end{tabular}


Table 2

Composition (a) of Bond Holdings by MMFs

(percent of total assets)

\begin{tabular}{|c|c|c|c|c|c|}
\hline $\begin{array}{l}\text { Types } \\
\text { of Bonds }\end{array}$ & 1978 & 1979 & 1980 & 1981 & $\begin{array}{l}\text { Aver age } \\
78-81 \\
\end{array}$ \\
\hline $\begin{array}{l}\text { TBs } \\
\text { CDs } \\
\text { CPs } \\
\text { Others (b) } \\
\text { Total }\end{array}$ & $\begin{array}{l}14.6 \\
31.3 \\
30.7 \\
23.4 \\
100\end{array}$ & $\begin{array}{l}11.7 \\
20.9 \\
35.8 \\
31.6 \\
100\end{array}$ & $\begin{array}{l}15.7 \\
16.0 \\
40.0 \\
28.3 \\
100\end{array}$ & $\begin{array}{l}13.2 \\
16.1 \\
34.5 \\
36.2 \\
100\end{array}$ & $\begin{array}{l}13.8 \\
21.2 \\
35.3 \\
29.9 \\
100\end{array}$ \\
\hline
\end{tabular}

Notes:

a. Average of percentage holdings of each type of bond by 34 sample MMFs.

b. Includes Repurchase Agreement, Banker's Acceptance, Eurodollar CDs, etc. 
Table 3

Direction of Prescribed Changes in Average Maturity of MMF Portfolios Holding Different Bonds as Measured by the Yield Method

Table 3(a) CP vs. CD

Direction of

Changes for

Direction of Changes

CD Portfolios for CP Portfolios Decrease Increase

Total

Decrease

Increase

71

19

17

88

Total

90

39

58

$56 \quad 146$

Table 3(b) CP vs. TB

\begin{tabular}{lccr} 
& \multicolumn{2}{c}{ CP Portfolios } & \\
\cline { 2 - 3 } TB Portfolios & Decrease & Increase & Total \\
\hline Decrease & 64 & 18 & 82 \\
Increase & 38 & 43 & 81 \\
Total & 102 & 61 & 163
\end{tabular}

Table 3(c) TB vs. CD

\begin{tabular}{lccc} 
& \multicolumn{2}{c}{ CD Portfolios } & \\
\cline { 2 - 3 } TB Portfolios & Decrease & Increase & Total \\
\hline & 74 & 19 & 93 \\
Decrease & 30 & 58 & 88 \\
Increase & 104 & 77 & 181
\end{tabular}


Table 4

Total Number of Weekly Observations for the Period 1978-1981 Broken Down by Direction of Indicated Maturity Change and Agreement Between the Types of Bond Held and Experiments (Yield and Rate of Return)

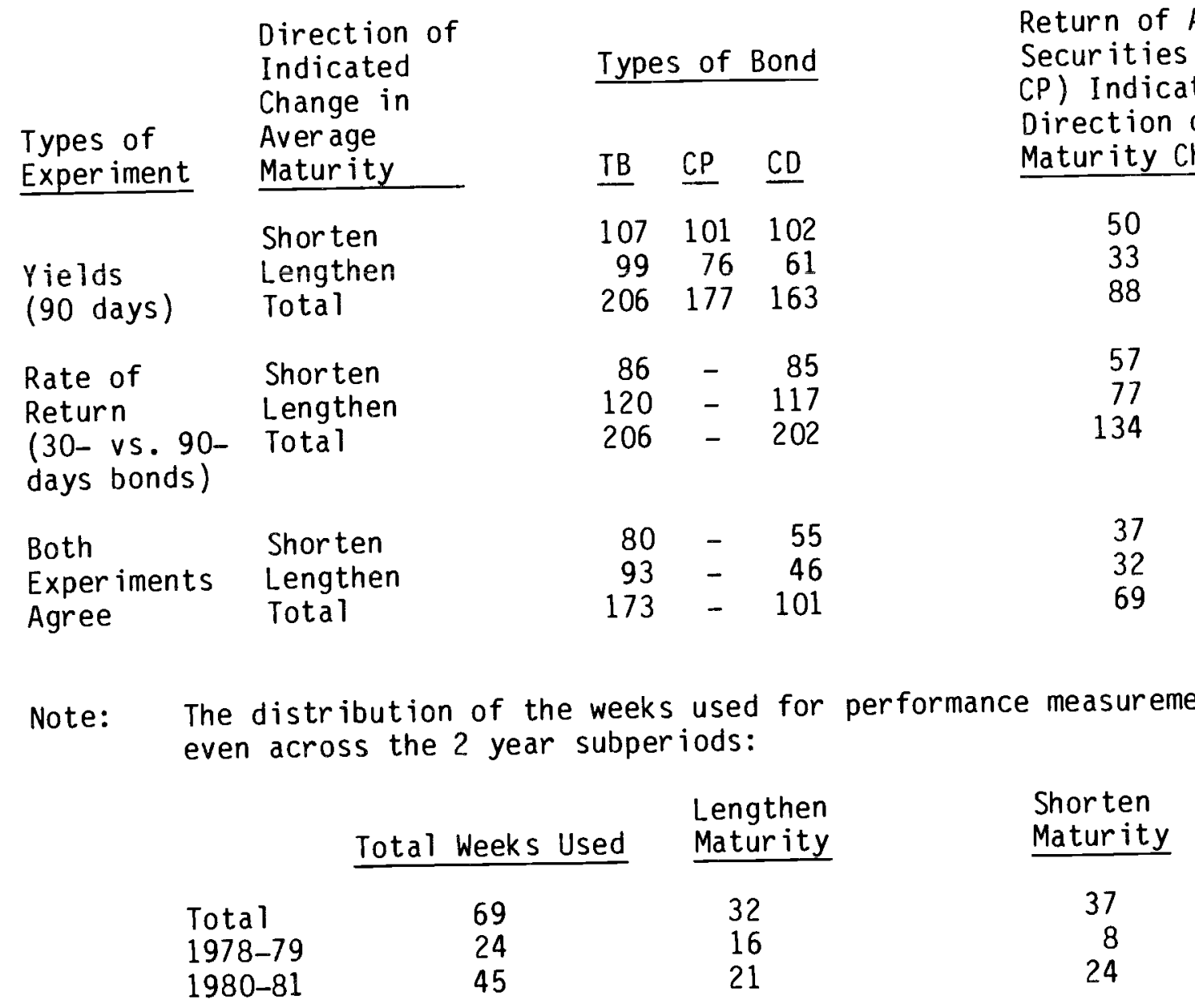


Table 5

Simulations of the Results of Aggregation of MMFs Portfolios Using Actual Data from the 34 MMFs in the Sample

Breaking the Sample into 8 Superior and 26 Inferior MMF Managements
Breaking the Sample into 4 Superior and 30 Inferior MMF Managements

$$
\begin{aligned}
& M=8, n=26, n / m=3.25 \quad m=4, n=30, n / m=7.5 \\
& \text { Average Statistics in the Actual Sample } \\
& \text { for the Superior Managements } \\
& \mathrm{P}_{1}+\mathrm{P}_{2}=1.31 ; \mathrm{e}=.155 \quad \mathrm{P}_{1}+\mathrm{P}_{2}=1.38 ; \mathrm{e}=.190 \\
& \text { Average Statistics in the Actual Sample } \\
& \text { for the Inferior Managements } \\
& P_{1}+P_{2}=1.05 ; \quad \mathrm{e}=.025 \\
& P_{1}+P_{2}=1.07 ; e=.035 \\
& \text { Assuming Conditional Independence and Using } e_{n}, e_{m}, m, n \\
& \text { from the Sample, Equation (8) Predicts the Following } \\
& \text { Aggregation Results } \\
& \rho=.55 \quad \rho=.53 \\
& P_{1}+P_{2}=1.55 ; \quad e=.275 \\
& P_{1}+P_{2}=1.53 ; \quad e=.265
\end{aligned}
$$

No

Yes

(a). The partial derivative of $\rho$ in (8) with respect to $n$ implies that if

$$
\frac{n}{m}>\frac{\left(e_{m}-2 e_{n}-\left(4 e_{m} e_{n}\right)\left(1-2 e_{m}\right)\right.}{e_{n}\left(1-4 e_{n}^{2}\right)}
$$

then adding an inferior forecaster will actually improve the quality of the average forecast. 
Table 6

Realized Rates of Return on T-bill Strategies

with 30- and 90-Day Maturities for 1978-1981

$\underline{\text { Strategy }}$

Hold 30-Day Bill Mean (percent annualized)

St andard Deviation

Hold 90-Day Bill

Mean

Standard Deviation

Switch with Perfect Foresight

Mean

Premium Over 30-Day Bill

Difference Between 90and 30-Day Rates

Mean

Standard Deviation $\underline{1978-81} \quad \underline{1980-81}$

$\underline{1978-79}$

$\begin{array}{rrr}10.26 & 12.14 & 8.41 \\ .55 & .60 & .34\end{array}$

10.80

1.04

13.32

1.26

8.31

.56

12.28

2.02

15.38

3.24

9.20

.79

.54

.72

1.19

.94
$-.10$

.38 
Table 7

Estimates of the Forecasting Ability of MMFs

for the Period 1978-1981

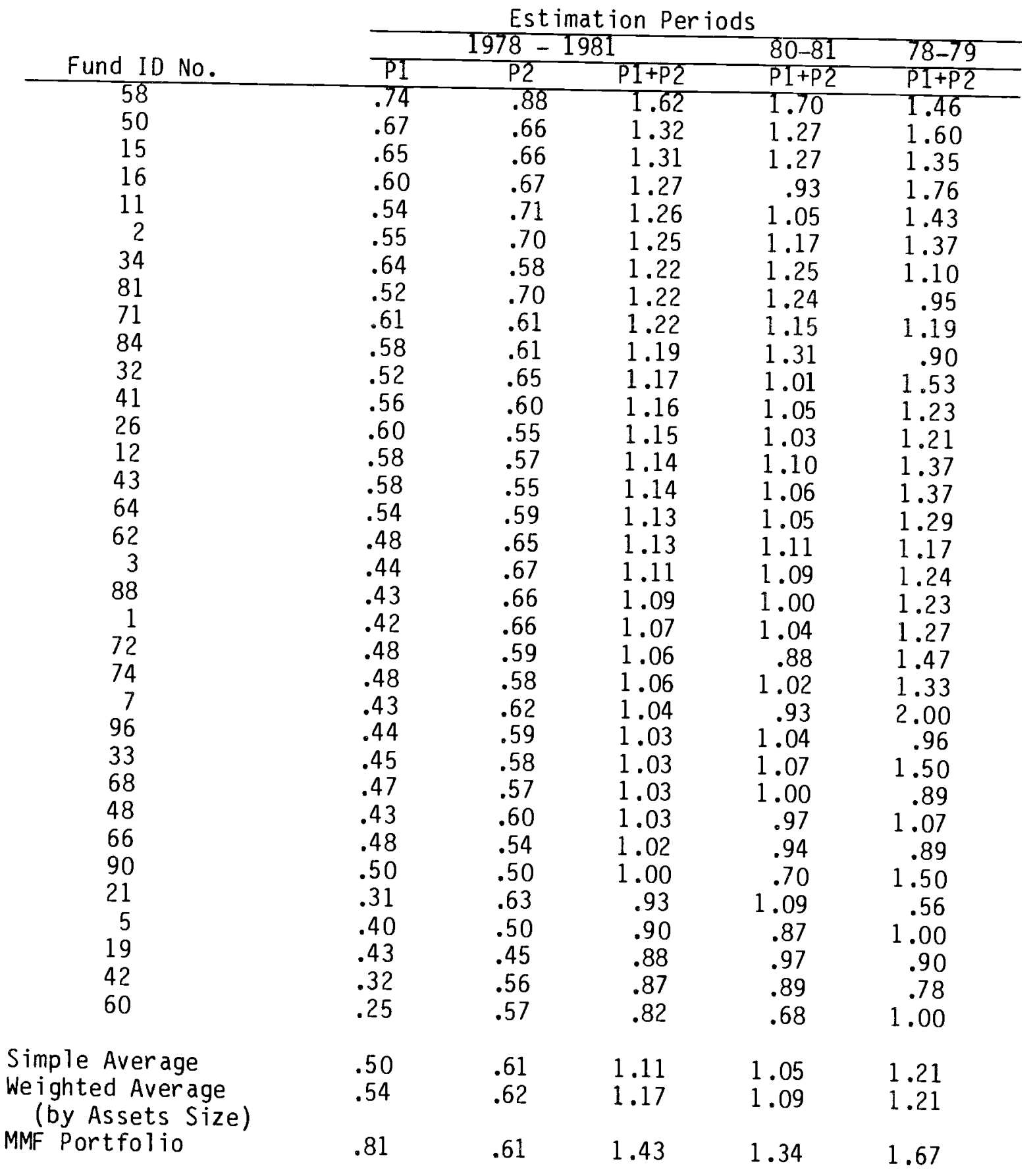




\section{Table 8}

Mean and Standard Deviation of the Correlation Coefficients Between Conditional Forecasts

$$
\operatorname{Corr}(Y i, Y j)
$$

Mean S.D.

A11 34 MMFs

Shortening of

Maturity Is

Favored

.179

Lengthening of

Maturity Is

Favored

$(+)$

$.046 \quad .206$

Top 8 MMFs
$\begin{aligned} & \text { Shortening }(-) \\ & \text { Lengthening }(+)\end{aligned}$
\[ =1 \text { if maturity shortened } \]
0 if maturity is lengthened




\section{Table 9}

Average Weekly Changes in the MMF Portfolio Average Maturity

( in days, 34 MMFs, 1978-1981)

$\begin{array}{ll}\text { For the Weeks } & \text { For All Weeks } \\ \text { Used to } & \text { in the Period } \\ \text { Measure } & (208 \text { Weeks in } \\ \text { Performance } & 1978-81)\end{array}$

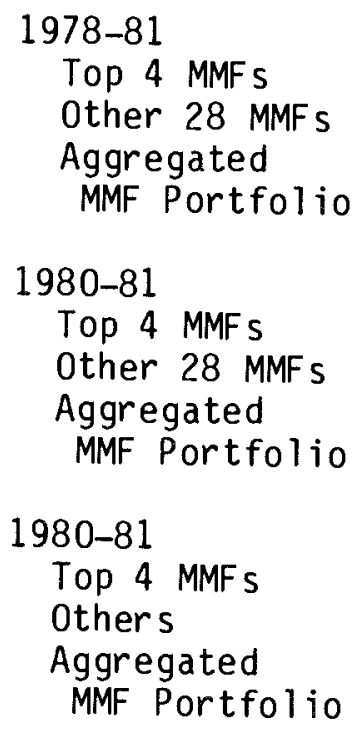

1.86

4.18

2.44 
Table 10

Average Magnitude of Changes in the 90-Day Yield to Maturity and Difference in Realized Rates of Return Between 90- and 30-Day Securities

(percent 1978-1981)

Type of Weeks and Indicated Direction of Maturity Change

Al1 Week s Shorten Lengthen

Weeks Used for Performance Measurements Shorten Lengthen
Yield Changes (90-Day Maturity)

Rate of Return Differences (90-vs. 30-Days)

\begin{tabular}{rrrrr} 
TB & $C D$ & $C P$ & TB & CD \\
\hline & & & & \\
.244 & .213 & .270 & -.023 & -.028 \\
-.239 & -.265 & -.462 & .029 & .022
\end{tabular}

\begin{tabular}{rrrrr}
.674 & .693 & .439 & -.056 & -.061 \\
-.662 & -.838 & -.784 & .075 & .097 \\
\hline
\end{tabular}


Table 11

Performance, Asset Size and Growth During 1978-81

(Simple and Spearman Rank Correlation Coefficients)

\begin{tabular}{lrcccc} 
& AST78 & AST81 & Growth & AVAST & $P_{1}+P_{2}$ \\
\cline { 2 - 6 } AST78 & & & & & \\
AST81 & .72 & -70 & -.29 & .69 & .22 \\
Growth & -.49 & .18 & .08 & .99 & .24 \\
AVAST & .74 & .99 & -15 & .06 & -.28 \\
P* & .21 & .03 & -.14 & .04 & .24
\end{tabular}

Upper right corner: Simple correlation coefficients.

Down left: Spearman rank correlation coefficients.

AST78(AST81): Asset size of a MMF in 1978(1981)

AVAST: Average of AST78 and AST81 


\section{Footnotes}

1. See Merton (1980) and Henriksson and Merton (1981) for references.

2. For example, as of June 1981 the total market value of short term financial assets (i.e., T-bills of up to 6 month maturity, CPs, CDs and bankers' acceptances) was 574.5 billion dollars and the total market value of the assets held by money market funds amounted to 126.4 billion dollars, dispersed among slightly more than 100 funds.

3. We do not confront the question of whther MMFs should even attempt to do so. One can argue that MMFs should precommit themselves to specific maturities and short-term instruments and leave the interest rates forecasting theatre to managers of interest futures funds. It is also possible that these funds restricted themselves in changing the ir portfolio maturity due to risk consideration.

4. We relegate the discussion of the identity of the bonds to a later section.

5. This restriction of the nature of the change in the yield curve implies, implicitly, the expectation hypothesis, for if the yield curve incorporates liquidity premia,. then the lefthand side in (4) must include the adjustment term for the liquidity premium.

6. See Kendall and Stuart (1977, pp. 536-538), as cited by Ferri and Oberhelman (1981b).

7. This portfolio is also identical to a $\$ 1$ share in the risky portfolio plus a put option on that share with a maturity $T$ and exercise price $R(t)$.

8. The expression in (14) assumes that the manager collects fees (if any) at the end of the period. Merton assumes that in equilibrium, fees equal to the economic value are decucted up front, so that per dollar invested by client, the value is $c(t) /[1+c(t)]$. 
9. If the holding period, $T$ (which is in our case one week), is short relative to the maturity of the bond (30 or 90 days in our case), then the assumption of a constant mean and variance rates $\left(\alpha, \sigma^{2}\right)$ for the price dynamics is reasonable.

10. Note that over the period 1978-79 the average maturity of the MMFs in the sample was around 70-90 days, which was reduced to around 25-35 days during the next subperiod.

11. Merton's results for the market portfolio with, say, 20 percent annual standard deviation is 43.7 percent.

12. This result requires the assumption that securities are priced to satisfy the security market line.

13. Note that changing the benchmark bonds will also change the variance of the rate difference in $c(t)$ and leave the economic value of the forecast unchanged - if the assumption of the linearity of rates in maturity is preserved. 


\section{References}

Bodie, Z., A. Kane, and R. McDonald, "Why Are Real Interest Rates So High," National Bureau of Economic Research, Inc., Working Paper No. 1141, June 1983.

Donoghue's Money Fund Reports, Donoghue's Money Fund Directory, Holliston, Mass., various issues.

Ferri M.G., and H.D. Oberhelman, "How Well Do Money Markets Perform," Journal of Portfolio Management, Spring 1981 (1981a).

and

"A Study of the Management of Money Market Mutual Funds:

1975-1980," Financial Management, Autumn 1981 (1981b).

Henriksson, R.D. and R.C. Merton, "On Market Timing and Investment Performance II: Statistical Procedures for Evaluating Forecasting Ski11s," Journal of Business, Vol. 54, No. 4, 1981.

Kendal1, M.G. and A. Stuart, The Advanced Theory of Statistics, Charles Griffin a Co., Ltd., London, 1977.

Merton, R.C., "The Theory of Rational Option Pricing," Bell Journal of Economics and Management, Spring 1973.

"On Estimating the Expected Returns on the Market," Journal of Financial Economics, 1980.

"On Market Timing and Investment Performance I: An Equilibrium Theory of Value for Market Forecasts," Journal of Business 54, July 1981.

Ro11, R., "Ambiguity When Performance is Measured by the Security Market Line," Journal of Finance, September 1978 